\title{
RESEARCH
}

Open Access

\section{The albumin-to-alkaline phosphatase ratio as an independent predictor of future non- alcoholic fatty liver disease in a 5-year longitudinal cohort study of a non-obese Chinese population}

\author{
Guotai Sheng ${ }^{1}$, Nan Peng ${ }^{1}$, Chong Hu${ }^{2}$, Ling Zhong ${ }^{3}$, Mingchun Zhong ${ }^{1}$ and Yang Zou ${ }^{1 *}$ id
}

\begin{abstract}
Background: The albumin-to-alkaline phosphatase ratio (AAPR) is a newly developed index of liver function, but its association in patients with non-alcoholic fatty liver disease (NAFLD) has not been established. The aim of this study was to investigate the association between the AAPR and NAFLD in a non-obese Chinese population.
\end{abstract}

Methods: The study included 10,749 non-obese subjects without NAFLD at baseline and divided them into quintiles according to the AAPR. A Cox multiple regression model was used to examine the association between the AAPR and its quintiles and the incidence of NAFLD.

Results: The average age of the study population was $43.65 \pm 15.15$ years old. During the 5 -year follow-up, 1860 non-obese subjects had NAFLD events. In the Cox multiple regression model, after adjusting the model according to important risk factors, the AAPR and NAFLD risk were independently correlated, and with a gradual increase in the AAPR, the NAFLD risk decreased gradually (HR: 0.61, 95\% Cl: 0.47, 0.81; P-trend< 0.0001). Additionally, there were significant interactions between the AAPR and BMl, blood pressure and lipids (P-interaction < 0.05). Stratified analysis showed that the risk of AAPR-related NAFLD decreased in people with normal blood pressure and lipid levels, while the risk of AAPR-related NAFLD increased abnormally in people who were underweight.

Conclusions: This longitudinal cohort study provides the first evidence that the AAPR is an independent predictor of future NAFLD events in non-obese people. For non-obese people with a low AAPR, especially those with BMI < $18.5 \mathrm{~kg} / \mathrm{m}^{2}$, more attention should be given to the management of risk factors for NAFLD to prevent future NAFLD.

Keywords: Albumin-to-alkaline phosphatase ratio, AAPR, Non-obese, Risk factors, Non-alcoholic fatty liver disease, Longitudinal cohort study

\footnotetext{
* Correspondence: jxyxyzy@163.com

${ }^{1}$ Cardiology Department, Jiangxi Provincial People's Hospital Affiliated to

Nanchang University, Nanchang 330006, China

Full list of author information is available at the end of the article
}

\section{$\triangle B M C$}

(c) The Author(s). 2021 Open Access This article is licensed under a Creative Commons Attribution 4.0 International License, which permits use, sharing, adaptation, distribution and reproduction in any medium or format, as long as you give appropriate credit to the original author(s) and the source, provide a link to the Creative Commons licence, and indicate if changes were made. The images or other third party material in this article are included in the article's Creative Commons licence, unless indicated otherwise in a credit line to the material. If material is not included in the article's Creative Commons licence and your intended use is not permitted by statutory regulation or exceeds the permitted use, you will need to obtain permission directly from the copyright holder. To view a copy of this licence, visit http://creativecommons.org/licenses/by/4.0/ The Creative Commons Public Domain Dedication waiver (http://creativecommons.org/publicdomain/zero/1.0/) applies to the data made available in this article, unless otherwise stated in a credit line to the data. 


\section{Background}

Non-alcoholic fatty liver disease (NAFLD) is a widespread chronic liver disease without a history of heavy alcohol consumption. It covers the development process of chronic diseases from simple steatosis of the liver to more severe non-alcoholic steatohepatitis and liver cirrhosis [1, 2]. However, in recent years, increasing evidence has shown that the disease burden of NAFLD comes not only from liver disease but also from NAFL D-related cardiovascular disease, metabolic disease and kidney disease [2-5]. NAFLD is a multi-system disease that affects multiple organs of the body and metabolic regulatory pathways $[6,7]$.

NAFLD is generally thought to be caused by overweight and obesity [2, 8], and in the past, related studies were mainly conducted in obese people. However, in recent years, an increasing number of studies have focused on non-obese NAFLD [9-11]. In a recent meta-analysis of more than 2 million people in 24 countries, nonobese people accounted for $40.8 \%$ of NAFLD patients globally [12], and in Asia, this situation seems to be more common $[13,14]$. Additionally, a growing body of research suggests that people with non-obese NAFLD appear to be more prone to metabolic syndrome and progress to severe liver disease at a significantly faster rate $[15,16]$. Therefore, it may be important to identify non-obese people at risk of NAFLD as early as possible and to manage their metabolic status.

Monitoring liver function markers, blood glucose and lipid metabolic markers and abdominal ultrasound are the most commonly used methods to assess the risk of NAFLD [17]. Albumin (ALB) and alkaline phosphatase (ALP) are the main indexes often used to evaluate liver function in clinical practice, in which the level of ALB can reflect the protein synthesis ability of the liver; ALP is a hydrolytic enzyme widely distributed in various tissues of the human body. It is mainly concentrated in the liver. When liver injury occurs, the level of ALP in the circulation increases [18]. Recently, in a study of liver tumour disease comparing the effects of different liver function measures on long-term prognosis, it was found that the albumin-to-alkaline phosphatase ratio (AAPR) showed the highest C-index compared to other liver function measures [19]. This result has also been verified in some similar studies $[20,21]$. On the other hand, in the early stage of NAFLD, ALB and routine liver enzymes are usually normal [22], which makes it difficult for clinicians to identify groups at high risk of NAFLD based only on liver function tests. Therefore, the purpose of this study was to identify a population at high risk of NAFLD as early as possible with the help of some commonly used clinical liver function markers. At present, the link between the AAPR and NAFLD has not been established. Therefore, based on a large-sample longitudinal non-obese cohort, the following hypotheses are proposed in this study: can the AAPR be used to predict future NAFLD events in the non-obese Chinese population?

\section{Methods \\ Study design}

The longitudinal cohort data of this study come from the Dryad database, which is open and free, allowing researchers to use database services freely according to the purpose of the study. According to the terms of service of the database, the data sources were quoted and marked in this study [23]. The packet provides data on 16,173 non-obese subjects without NAFLD, liver disease, diabetes, history of heavy drinking and baseline medication use recruited by Wenzhou People's Hospital from Jan 2010 to Dec 2014. The study scheme was approved by the institutional review boards of Wenzhou People's Hospital, informed consent was obtained from the subjects, and a 5-year follow-up was completed. The detailed study design has been mentioned in previous studies [24]. In this study, a secondary analysis was carried out based on the NAFLD longitudinal cohort, and the following were some design elements: study exposure factors: AAPR; outcome: new-onset NAFLD events; subjects: 10,749 non-obese subjects were analysed after excluding the subjects with ALP and ALB deletions.

\section{Data collection}

As mentioned earlier [24], baseline clinical data such as age, sex, height, weight, and blood pressure were recorded using a uniform health questionnaire; blood pressure was measured in a sitting position in a quiet environment using a standard electronic sphygmomanometer, and systolic and diastolic blood pressures (S/DBP) were recorded. Body mass index (BMI) was calculated as height divided by weight squared. The measurement of biochemical indexes was tested by automatic analytical instruments (Abbott AxSYM) through standard methods. The biochemical parameters included in this study were as follows: ALP, ALB, blood urea nitrogen (BUN), aspartate aminotransferase (AST), creatinine $(\mathrm{Cr})$, triglyceride (TG), uric acid (UA), total protein (TP), total cholesterol (TC), direct bilirubin (DBIL), fasting plasma glucose (FPG), gamma glutamyl transferase (GGT), globulin (GLB), low-density lipoprotein cholesterol (LDL-C), alanine aminotransferase (ALT), total bilirubin (TB), and highdensity lipoprotein cholesterol (HDL-C).

\section{Diagnosis of NAFLD}

Subjects were assessed for NAFLD by abdominal ultrasound once a year during follow-up. The diagnosis of NAFLD was based on the diagnostic guidelines issued by the Chinese Liver Disease Association in 2010 [25]. The main contents of the evaluation include (a) diffuse 
high echo of the liver relative to the kidney and spleen; (b) echo attenuation of deep liver; (c) liver mildly to moderately enlarged, margin rounded obtuse; (d) liver blood flow signal is weakened; and (e) the right lobe and diaphragm are obscured or only partially shown. The diagnostic criteria for NAFLD needed to meet the echo characteristics of the above item (a) plus any one of the other items.

\section{Statistical analysis}

All statistical analyses in this study were conducted on Empower Stats (R, version 2.20) and statistical software $\mathrm{R}$ language (version 3.4.3), and a $P$-value of $<0.05$ (2-tailed) was considered to indicate statistical significance. The main steps were divided into the following three steps:

Step one: The baseline characteristics of all patients were stratified according to the AAPR quintile, and the continuous variables were expressed as the mean (standard deviation) or median (interquartile range). One-way ANOVA or the Kruskal-Wallis $\mathrm{H}$ test was used for intergroup comparisons. The qualitative data were summarized as frequencies or percentages, and the chi-square test was used to check the differences between groups.

Step two: In the population diagnosed with NAFLD, linear regression was used to check the correlation between the AAPR and baseline data (Supplementary Table 1, Additional file 1). The variables significantly related to the AAPR may be auxiliary factors of the association between the AAPR and NAFLD and were included in the model as important adjustment variables in Cox multiple regression analysis [26]. Additionally, before establishing the multiple regression model, the collinearity between variables was checked, and the variance inflation factor (VIF) of each variable was calculated (Supplementary Table 2, Additional file 1). The variables with VIF $>5$ were regarded as collinear variables and could not be included in the multiple regression model [27].

Step three: The incidence of NAFLD in the five AAPR groups was estimated by the Kaplan-Meier curve, and the comparison between groups was made by the logrank test. To explore the association between the AAPR and NAFLD, a Cox multiple regression model was constructed, and the AAPR was input into the model to calculate the hazard ratio (HR) and 95\% confidence interval (CI) of NAFLD caused by each 1-unit increase [28]. Five models were used, with the crude model being unadjusted. Model 1 adjusted for the clinical baseline index (age, sex, height, BMI and SBP). Model 2 adjusted for model 1 plus liver function markers (GGT, ALT, AST, GLB, and TP). Since the AAPR is the ratio of ALB to ALP, in order to avoid the potential confounding effect between the AAPR and these two variables, ALB and ALP were not included in model 2. Model 3 adjusted for model 2 plus the blood glucose metabolism marker FPG and kidney function marker Cr. Model 4 adjusted for model 3 plus lipid metabolic markers (TG, HDL-C, and LDL-C). Additionally, considering that the correlation between the AAPR and NAFLD may be different under different conditions $[4,5,11]$, the researchers also conducted an exploratory hierarchical analysis in some subgroups and checked the differences between different hierarchical groups by the likelihood ratio test to determine whether there was an interaction.

\section{Results}

\section{Characteristics of the subject}

Among the 16,173 patients enrolled in the study, 10,749 non-obese subjects fulfilled the inclusion criteria for the present post hoc analysis. The baseline mean age was $43.65 \pm 15.15$ years, with slightly more male subjects than female subjects $(54.90 \%$ vs $45.10 \%)$. Table 1 summarizes the baseline characteristics grouped by AAPR quintiles. In the group with a low AAPR, there were more males than females, and with an increase in the AAPR, the number of males decreased gradually, while the number of females increased gradually. In the group with a higher AAPR, the average BMI, weight, age, TC, AST, ALP, TP, GLB, BUN, LDL-C, GGT, Cr, UA, ALT, FPG, TG, SBP and DBP of the subjects were lower than those in subjects with a lower AAPR. In contrast, ALB and HDL-C levels were higher in the groups with higher AAPR values (all $P<0.05$ ).

\section{Incidence of NAFLD}

During the 5-year follow-up, 1860 non-obese subjects had NAFLD events. Among them, the NAFLD prevalence rates corresponding to the AAPR quintile grouping were Q1: 23.72\%, Q2: 20.33\%, Q3: 17.50\%, Q4: 13.49\%, and Q5: $11.48 \%$. With the gradual increase in the AAPR, the incidence of NAFLD gradually decreased. In addition, the probability of 5-year cumulative NAFLD events in the five AAPR groups was estimated by the Kaplan-Meier curve to be Q1: $52.93 \%$, Q2: 47\%, Q3: $43.65 \%$, Q4: $29.94 \%$ and Q5: 36.16\% (Fig. 1). With the increase in the AAPR, the cumulative incidence of NAFLD decreased gradually (logrank $P<0.001)$.

\section{Correlation analysis between the AAPR and baseline variables}

Linear regression analysis showed that age, height, weight, SBP, ALP, ALB, GGT, ALT, AST, TP, GLB, Cr and FPG were associated with the AAPR in the population with NAFLD $(P<0.05)$. This finding suggests that these variables that were significantly related to AAPR may be auxiliary factors associated with AAPR and NAFLD. 
Table 1 Characteristics of the subject

\begin{tabular}{|c|c|c|c|c|c|c|}
\hline AAPR & $\mathrm{Q} 1(\geq 0.05, \leq 0.5)$ & $\mathrm{Q} 2(>0.5, \leq 0.59)$ & $\mathrm{Q} 3(>0.59, \leq 0.69)$ & $\mathrm{Q} 4(>0.69, \leq 0.81)$ & $\mathrm{Q} 5(>0.81)$ & $P$-value \\
\hline $\mathrm{N}(\%)$ & 2150 & 2150 & 2148 & 2150 & 2151 & \\
\hline Sex & & & & & & $<0.001$ \\
\hline Women & 919 (42.74\%) & $930(43.26 \%)$ & $968(45.07 \%)$ & $974(45.30 \%)$ & 1057 (49.14\%) & \\
\hline Men & 1231 (57.26\%) & $1220(56.74 \%)$ & 1180 (54.93\%) & 1176 (54.70\%) & $1094(50.86 \%)$ & \\
\hline NAFLD & & & & & & $<0.001$ \\
\hline No & 1640 (76.28\%) & 1713 (79.67\%) & 1772 (82.50\%) & $1860(86.51 \%)$ & $1904(88.52 \%)$ & \\
\hline Yes & $510(23.72 \%)$ & 437 (20.33\%) & $376(17.50 \%)$ & $290(13.49 \%)$ & $247(11.48 \%)$ & \\
\hline Age, years & $44.00(33.00-56.00)$ & $41.00(32.00-53.00)$ & $40.00(31.00-51.00)$ & $40.00(32.00-52.00)$ & $38.00(30.00-50.00)$ & $<0.001$ \\
\hline$A L P, U / L$ & 104.39 (26.44) & $80.66(6.10)$ & $70.04(4.96)$ & $60.56(4.51)$ & $47.12(7.12)$ & $<0.001$ \\
\hline GGT, U/L & $26.00(20.00-42.00)$ & $23.50(18.00-34.00)$ & $22.00(17.00-31.00)$ & $20.00(16.00-28.00)$ & $18.00(14.00-25.00)$ & $<0.001$ \\
\hline $\mathrm{ALT}, \mathrm{U} / \mathrm{L}$ & $19.00(14.00-27.00)$ & $18.00(13.00-24.00)$ & $16.00(12.00-23.00)$ & $15.00(12.00-21.00)$ & $14.00(11.00-19.00)$ & $<0.001$ \\
\hline AST, U/L & $23.00(20.00-28.00)$ & $22.00(19.00-26.00)$ & $22.00(19.00-25.00)$ & $21.00(18.00-24.00)$ & $20.00(17.00-23.00)$ & $<0.001$ \\
\hline TP, g/L & $73.96(4.66)$ & $73.78(4.22)$ & $73.89(4.13)$ & $74.01(4.10)$ & $73.63(4.13)$ & 0.024 \\
\hline$A L B, g / L$ & $43.70(41.70-45.60)$ & $44.60(42.60-46.20)$ & $44.80(42.90-46.50)$ & $45.00(43.30-46.70)$ & $45.00(43.30-46.80)$ & $<0.001$ \\
\hline$G L B, g / L$ & $30.15(27.52-33.00)$ & $29.20(26.80-31.67)$ & $29.00(26.70-31.50)$ & $29.00(26.60-31.40)$ & $28.40(26.10-30.90)$ & $<0.001$ \\
\hline $\mathrm{TB}, \mu \mathrm{mol} / \mathrm{L}$ & $11.00(8.80-14.30)$ & $11.40(9.00-14.55)$ & $11.80(9.20-14.80)$ & $11.70(9.30-15.00)$ & $11.30(8.80-14.50)$ & $<0.001$ \\
\hline $\mathrm{DBIL}, \mu \mathrm{mol} / \mathrm{L}$ & $2.00(1.40-2.70)$ & $2.00(1.50-2.70)$ & $2.10(1.50-2.80)$ & $2.10(1.50-2.90)$ & $2.00(1.50-2.70)$ & 0.003 \\
\hline BUN & $4.52(3.80-5.50)$ & $4.60(3.80-5.50)$ & $4.46(3.70-5.30)$ & $4.40(3.64-5.30)$ & $4.30(3.50-5.20)$ & $<0.001$ \\
\hline $\mathrm{Cr}, \mu \mathrm{mol} / \mathrm{L}$ & $88.00(75.25-99.00)$ & $86.00(74.00-96.00)$ & $84.00(72.00-95.00)$ & $79.00(68.00-93.00)$ & $75.00(66.00-90.00)$ & $<0.001$ \\
\hline UA, mmol/L & $312.07(86.01)$ & $308.58(84.48)$ & 303.51 (88.49) & $288.76(89.70)$ & $268.70(91.41)$ & $<0.001$ \\
\hline $\mathrm{FPG}, \mathrm{mmol} / \mathrm{L}$ & $5.15(4.84-5.55)$ & $5.08(4.80-5.44)$ & $5.07(4.80-5.41)$ & $5.05(4.79-5.33)$ & $4.99(4.76-5.29)$ & $<0.001$ \\
\hline $\mathrm{TC}, \mathrm{mmol} / \mathrm{L}$ & $4.67(0.80)$ & $4.63(0.73)$ & $4.61(0.75)$ & $4.62(0.71)$ & $4.56(0.72)$ & $<0.001$ \\
\hline $\mathrm{TG}, \mathrm{mmol} / \mathrm{L}$ & $1.30(0.97-1.79)$ & $1.26(0.93-1.76)$ & $1.17(0.88-1.65)$ & $1.09(0.81-1.54)$ & $0.97(0.74-1.33)$ & $<0.001$ \\
\hline $\mathrm{HDL}-\mathrm{C}, \mathrm{mmol} / \mathrm{L}$ & $1.40(0.35)$ & $1.40(0.35)$ & $1.43(0.36)$ & $1.50(0.37)$ & $1.54(0.36)$ & $<0.001$ \\
\hline LDL-C, mmol/l & $2.37(2.01-2.70)$ & $2.33(1.98-2.66)$ & $2.31(1.96-2.64)$ & $2.28(1.93-2.61)$ & $2.25(1.91-2.58)$ & $<0.001$ \\
\hline Height, m & $1.66(0.76)$ & $1.67(0.76)$ & $1.67(0.76)$ & $1.66(0.77)$ & $1.65(0.75)$ & $<0.001$ \\
\hline Weight, kg & $60.75(8.13)$ & $61.22(8.02)$ & $60.80(8.51)$ & $59.50(8.52)$ & $57.90(8.62)$ & $<0.001$ \\
\hline $\mathrm{BMI}, \mathrm{kg} / \mathrm{m}^{2}$ & $22.15(20.61-23.48)$ & $22.09(20.69-23.45)$ & $21.89(20.32-23.33)$ & $21.49(19.93-23.04)$ & $21.16(19.66-22.84)$ & $<0.001$ \\
\hline $\mathrm{SBP}, \mathrm{mmHg}$ & $128.56(17.84)$ & $125.25(17.24)$ & $123.16(16.72)$ & $120.42(15.77)$ & $117.03(15.28)$ & $<0.001$ \\
\hline $\mathrm{DBP}, \mathrm{mmHg}$ & 76.09 (10.62) & 74.87 (10.28) & $74.07(10.20)$ & 73.05 (10.16) & 71.16 (9.83) & $<0.001$ \\
\hline
\end{tabular}

Values are $\mathrm{n}(\%)$ or mean (standard deviation) or median (interquartile range); Abbreviations: AAPR Albumin-to-alkaline phosphatase ratio, BMI Body mass index, BUN Blood urea nitrogen, $\mathrm{Cr}$ Creatinine, UA Uric acid, FPG Fasting plasma glucose, TC Total cholesterol, TG Triglyceride, HDL-C High-density lipoprotein cholesterol, LDL-C Low-density lipoprotein cholesterol, ALP Alkaline phosphatase, GGT Gamma-glutamyl transferase, ALT Alanine aminotransferase, AST Aspartate aminotransferase, TP Total Protein, ALB Albumin, GLB Globulin, TB Total bilirubin, DBIL Direct bilirubin, DBP Diastolic blood pressure, SBP Systolic blood pressure

\section{Association between the AAPR and NAFLD}

To improve the model's ability to identify the risk of NAFLD, the researchers established a Cox multiple regression model (Table 2). In the unadjusted model, there was a negative correlation between the AAPR and the risk of NAFLD, and the trend of NAFLD decreased with an increase in the AAPR (HR: 0.26, 95\% CI: $0.20,0.33 ; P$-trend <0.0001). After adjusting for the clinical baseline index (model 1), the negative correlation between the AAPR and NAFLD weakened, and the NAFLD risk corresponding to the AAPR quintile showed the same downward trend as before
(HR: 0.41, 95\% CI: 0.31, 0.53; P-trend < 0.0001). Then, after further adjustment for liver function markers in model 2, the association between the two was further reduced, and the negative correlation trend remained the same as before. Model 3 further adjusted for the blood glucose metabolism marker FPG and kidney function marker $\mathrm{Cr}$, and the degree of negative correlation between the AAPR and NAFLD remained basically unchanged (HR: 0.54, 95\% CI: 0.41, 0.72; Ptrend $<0.0001)$. Finally, after further adjusting for the lipid metabolism markers (TG, HDL-C, and LDL-C) in the Cox multiple regression model, it was found 


$$
\mathrm{AAPR} \text { quintiles } \pm \mathrm{Q} 1 \pm \mathrm{Q} 2 \pm \mathrm{Q} 3 \pm \mathrm{Q} 4 \pm \mathrm{Q} 5
$$

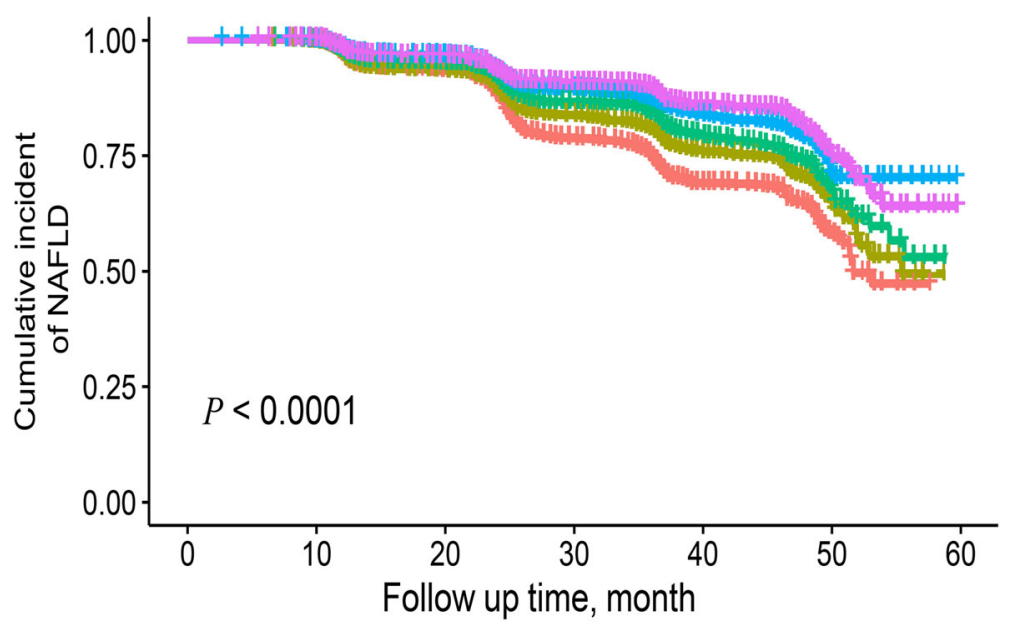

Number at risk

\begin{tabular}{|c|c|c|c|c|c|c|}
\hline $\begin{array}{l}\text { Q1 } \\
\text { Q2 } \\
\text { Q3 } \\
\text { Q4 } \\
\text { Q5 }\end{array}$ & $\begin{array}{l}2150 \\
2150 \\
2148 \\
2150 \\
2151\end{array}$ & $\begin{array}{l}2129 \\
2127 \\
2121 \\
2124 \\
2127\end{array}$ & $\begin{array}{l}1827 \\
1835 \\
1853 \\
1879 \\
1852\end{array}$ & $\begin{array}{c}966 \\
1073 \\
1060 \\
1054 \\
986\end{array}$ & $\begin{array}{l}474 \\
581 \\
612 \\
632 \\
527\end{array}$ & $\begin{array}{c}97 \\
122 \\
130 \\
113 \\
119\end{array}$ \\
\hline & 0 & 10 & 20 & 30 & 40 & 50 \\
\hline
\end{tabular}

Fig. 1 Kaplan-Meier curves compared the cumulative incidence of NAFLD at 5 years of follow-up after grouping by AAPR quintile (log-rank $P<$ 0.0001). NAFLD: non-alcoholic fatty liver disease; AAPR: albumin-to-alkaline phosphatase ratio; Q1: Quintile 1; Q2: Quintile 2; Q3: Quintile 3; Q4: Quintile 4; Q5: Quintile 5

that for each one-unit increase in the AAPR, the risk of NAFLD decreased by 39\% (HR: 0.61, 95\% CI: 0.47, $0.81, P$-trend $<0.0001)$. Additionally, in the AAPR quintile groups, the group with the highest AAPR had a reduction in the NAFLD risk by $19 \%$ compared with the group with the lowest AAPR.

\section{Subgroup analysis}

In the exploratory subgroup analysis, the clinical baseline index data, kidney function index, lipid metabolic index, blood glucose metabolism index and liver function index were stratified according to the clinical cutoff points. The HR and 95\% CI between different

Table 2 Association between AAPR and NAFLD in different models

\begin{tabular}{|c|c|c|c|c|c|}
\hline & \multicolumn{5}{|l|}{ HR $(95 \% \mathrm{Cl}) P$-value } \\
\hline & Crude model & Model 1 & Model 2 & Model 3 & Model 4 \\
\hline AAPR & $0.26(0.20,0.33)<0.0001$ & $0.41(0.31,0.53)<0.0001$ & $0.52(0.40,0.69)<0.0001$ & $0.54(0.41,0.72)<0.0001$ & $0.61(0.47,0.81) 0.0004$ \\
\hline \multicolumn{6}{|c|}{ AAPR (Quintile) } \\
\hline Q1 & Ref & Ref & Ref & Ref & Ref \\
\hline Q2 & $0.80(0.70,0.91) 0.0005$ & $0.81(0.72,0.93) 0.0017$ & $0.89(0.78,1.02) 0.0874$ & $0.90(0.79,1.02) 0.0999$ & $0.91(0.80,1.04) 0.1490$ \\
\hline Q3 & $0.67(0.59,0.77)<0.0001$ & $0.73(0.64,0.83)<0.0001$ & $0.82(0.71,0.94) 0.0045$ & $0.83(0.72,0.95) 0.0075$ & $0.85(0.74,0.98) 0.026$ \\
\hline Q4 & $0.52(0.45,0.60)<0.0001$ & $0.61(0.53,0.71)<0.0001$ & $0.68(0.58,0.79)<0.0001$ & $0.66(0.57,0.77)<0.0001$ & $0.73(0.63,0.85)<0.0001$ \\
\hline Q5 & $0.47(0.40,0.55)<0.0001$ & $0.59(0.84,0.90)<0.0001$ & $0.67(0.57,0.78)<0.0001$ & $0.63(0.53,0.74)<0.0001$ & $0.72(0.61,0.85)<0.0001$ \\
\hline$P$-trend & $<0.0001$ & $<0.0001$ & $<0.0001$ & $<0.0001$ & $<0.0001$ \\
\hline
\end{tabular}

Abbreviations: Cl Confidence interval, HR Hazard ratios, AAPR Albumin-to-alkaline phosphatase ratio

Crude model adjusted for none; model 1 adjusted for sex, age, height, BMI and SBP; model adjusted for model 1 plus liver function markers (GGT, ALT, AST, GLB, TP); model 3 adjusted for model 2 plus blood glucose metabolism marker FPG and kidney function marker Cr; model 4 adjusted model 3 plus lipid metabolic markers (TG, HDL-C, LDL-C) 
Table 3 The effect size of AAPR on NAFLD in prespecified and exploratory subgroups in each subgroup

\begin{tabular}{|c|c|c|c|c|}
\hline Characteristic & No. of participants & $\mathrm{HR}(95 \% \mathrm{Cl})$ & $P$-value & $P$-interaction \\
\hline \multicolumn{5}{|c|}{ Clinical baseline subgroup } \\
\hline Age (years) & & & & 0.1504 \\
\hline$<30$ & 2016 & $0.80(0.40,1.61)$ & 0.5334 & \\
\hline$\geq 30,<45$ & 4220 & $0.70(0.47,1.02)$ & 0.0623 & \\
\hline$\geq 45,<60$ & 2740 & $0.37(0.22,0.63)$ & 0.0002 & \\
\hline$\geq 60$ & 1754 & $0.82(0.42,1.61)$ & 0.5648 & \\
\hline Sex & & & & 0.9157 \\
\hline Men & 5891 & $0.61(0.43,0.88)$ & 0.0073 & \\
\hline Women & 4839 & $0.63(0.42,0.94)$ & 0.0252 & \\
\hline $\mathrm{BMl}, \mathrm{kg} / \mathrm{m}^{2}$ & & & & 0.0076 \\
\hline$\leq 18.5$ & 821 & $86.13(5.86,968.98)$ & 0.0012 & \\
\hline $18.6-25$ & 9909 & $0.60(0.46,0.79)$ & 0.0003 & \\
\hline $\mathrm{SBP}, \mathrm{mmHg}$ & & & & 0.0292 \\
\hline$<140$ & 9076 & $0.54(0.40,0.74)$ & 0.0001 & \\
\hline$\geq 140$ & 1657 & $0.94(0.70,1.28)$ & 0.7140 & \\
\hline $\mathrm{DBP}, \mathrm{mmHg}$ & & & & 0.0003 \\
\hline$<90$ & 9857 & $0.48(0.35,0.65)$ & $<0.0001$ & \\
\hline$\geq 90$ & 876 & $1.15(0.89,1.49)$ & 0.2748 & \\
\hline \multicolumn{5}{|c|}{ Liver function subgroup } \\
\hline GGT, U/L & & & & 0.8335 \\
\hline$<40$ & 8977 & $0.63(0.47,0.84)$ & 0.0016 & \\
\hline$\geq 40$ & 1770 & $0.67(0.41,1.08)$ & 0.0996 & \\
\hline $\mathrm{ALT}, \mathrm{U} / \mathrm{L}$ & & & & 0.8653 \\
\hline$<40$ & 10,109 & $0.61(0.46,0.81)$ & 0.0008 & \\
\hline$\geq 40$ & 640 & $0.57(0.24,1.34)$ & 0.1948 & \\
\hline AST, U/L & & & & 0.6524 \\
\hline$<40$ & 10,419 & $0.69(0.52,0.90)$ & 0.0063 & \\
\hline$\geq 40$ & 330 & $0.48(0.10,2.32)$ & 0.8708 & \\
\hline \multicolumn{5}{|c|}{ Kidney function subgroup } \\
\hline $\mathrm{Cr}, \mathrm{mmol} / \mathrm{L}$ & & & & 0.0247 \\
\hline$<108$ & 9809 & $0.23(0.17,0.30)$ & $<0.0001$ & \\
\hline$\geq 104$ & 937 & $1.37(0.68,2.76)$ & 0.3732 & \\
\hline \multicolumn{5}{|c|}{ Blood glucose metabolism subgroup } \\
\hline $\mathrm{FPG}, \mathrm{mmol} / \mathrm{L}$ & & & & 0.4721 \\
\hline$<6.1$ & 9931 & $0.58(0.43,0.77)$ & 0.0002 & \\
\hline$\geq 6.1$ & 799 & $0.76(0.38,1.55)$ & 0.4578 & \\
\hline \multicolumn{5}{|c|}{ Lipid metabolism subgroup } \\
\hline $\mathrm{TC}, \mathrm{mmol} / \mathrm{L}$ & & & & 0.0059 \\
\hline$<5.2$ & 8372 & $0.48(0.35,0.67)$ & $<0.0001$ & \\
\hline$\geq 5.2$ & 2358 & $0.93(0.70,1.23)$ & 0.5994 & \\
\hline $\mathrm{TG}, \mathrm{mmol} / \mathrm{L}$ & & & & 0.0155 \\
\hline$<1.7$ & 8348 & $0.48(0.33,0.68)$ & $<0.0001$ & \\
\hline$\geq 1.7$ & 2382 & $0.88(0.62,1.25)$ & 0.4658 & \\
\hline $\mathrm{HDL}-\mathrm{C}, \mathrm{mmol} / \mathrm{L}$ & & & & 0.0340 \\
\hline
\end{tabular}


Table 3 The effect size of AAPR on NAFLD in prespecified and exploratory subgroups in each subgroup (Continued)

\begin{tabular}{cllll}
\hline Characteristic & No. of participants & HR $(\mathbf{9 5} \% \mathbf{C l})$ & $P$-value & 0.2368 \\
\hline$<0.9$ & 392 & $2.01(0.63,6.38)$ & $<$-interaction \\
$\geq 0.9$ & 10,338 & $0.55(0.45,0.77)$ & $<0.0001$ \\
\hline
\end{tabular}

The above model adjusted for model 4

Note: In each case, the model is not adjusted for the stratification variable

Abbreviations: $\mathrm{Cl}$ Confidence, $\mathrm{HR}$ Hazard ratios;

hierarchical groups were analysed and calculated by a Cox regression model, and the difference between hierarchical groups was checked by the likelihood ratio test to determine whether there was an interaction. As shown in Table 3, there was a significant interaction between factors such as BMI, SBP, and DBP in the association between the AAPR and NAFLD in the clinical baseline data subgroup ( $P$-interaction $<0.05)$. Among them, the risk of AAPR-related NAFLD was abnormally increased in underweight people (BMI $<18.5 \mathrm{~kg} / \mathrm{m}^{2}$, HR: 86.13, 95\% CI: 5.86, 968.98; $P=0.0012$ ), and in people with normal blood pressure $(\mathrm{SBP}<140 \mathrm{mmHg}, \mathrm{DBP}<$ $90 \mathrm{mmHg}$ ), the risk of NAFLD associated with the AAPR was lower. In addition, significant interactions were observed in the lipid metabolism subgroup $(P$ interaction $<0.05$ ) in which the risk of AAPR-related NAFLD decreased significantly when there was no abnormal increase in blood lipids. However, no significant interaction was observed in the subgroups of age, sex, liver function, kidney function and blood glucose metabolism.

\section{Discussion}

To the best of our knowledge, this is the first report on the association between AAPR and new-onset NAFLD risk. In this study, after 5 years of follow-up, it was found that the increase in AAPR was negatively correlated with the risk of future NAFLD events in non-obese people. In the analysis of the Cox multiple regression model, the researchers determined that the AAPR was an independent predictor of NAFLD (HR: 0.61, 95\% CI: 0.47, 0.81, $P$ trend $<0.0001$ ).

The AAPR is the ratio of ALB to ALP, which can reflect some information regarding the two indicators at the same time, as well as information that cannot be reflected by these two indicators. In 2015, Chan et al. first reported that the AAPR can predict the poor prognosis of liver tumours, and its predictive performance is better than that of other liver markers [19]; some subsequent studies have also confirmed that this conclusion is reliable $[20,21]$. At present, the AAPR has been used as a new liver marker to evaluate the long-term prognosis of liver tumour diseases. In this study, the researchers found that the AAPR can also be used to predict NAFL $\mathrm{D}$ in chronic liver diseases; the longitudinal cohort design of this study better reflects that the AAPR can independently predict early NAFLD risk. It is well known that ALB and liver function abnormalities are rarely seen in the early stage of NAFLD, so it may be difficult to detect potential NAFLD risks through conventional biochemical markers [22]. The findings of this study provide a new idea for the prevention of newonset NAFLD.

In this study, the researchers also examined whether there were differences in AAPR-related NAFLD risk among people of different ages, sex, BMI, liver and kidney functions, blood pressure, blood glucose and blood lipids. The results showed that BMI, SBP, DBP, and lipid metabolism had significant interactions in the association between the AAPR and NAFLD ( $P$-interaction < 0.05). Among those with normal blood pressure and lipids, the risk of NAFLD associated with the AAPR was reduced $(\mathrm{SBP}<140 \mathrm{mmHg}, \mathrm{DBP}<90 \mathrm{mmHg}, \mathrm{TC}<5.2$ $\mathrm{mmol} / \mathrm{l}$, TG $<1.7 \mathrm{mmol} / \mathrm{l}$, HDL-C $\geq 0.9 \mathrm{mmol} / \mathrm{l}$ ). However, the risk of AAPR-related NAFLD was abnormally increased in underweight individuals $\left(B M I<18.5 \mathrm{~kg} / \mathrm{m}^{2}\right.$, HR: $86.13,95 \%$ CI: $5.86,968.98 ; P=0.0012$ ), which may be related to the significant decrease in skeletal muscle mass in underweight individuals. Related studies have shown that with a decrease in BMI, the skeletal muscle weight, skeletal muscle index and body fat of the extremities decrease significantly [29], and low muscle mass is independently positively correlated with NAFLD [30]. Additionally, underweight people not only have an increased risk of NAFLD but also have a lower BMI, which often indicates malnutrition, which will significantly increase the incidence of adverse events [31, 32]. It is suggested that individuals with $\mathrm{BMI}<18.5 \mathrm{~kg} / \mathrm{m}^{2}$ should increase BMI to a normal level and improve skeletal muscle quality through diet and healthy exercise as soon as possible.

At present, there are very few studies on the AAPR, and the mechanism of the association between the AAPR and NAFLD is not clear. The results of this study were similar to those of previous studies. In this study, a low AAPR was an independent predictor of new-onset NAFLD events. It is generally believed that a low AAPR often indicates that ALB is too low or that ALP is too high. ALB is a very important protein in serum; it not only maintains the colloidal osmotic pressure of the body but also participates in the storage and as a conveyor of many substances [33]. The level of ALB 
reflects human nutritional status and liver function [18, 33]. In addition, ALB is also involved in the regulation of inflammation and the immune response [34, 35]. ALP is a hydrolytic enzyme found mainly in the liver, bone, intestine, kidney and placenta. ALP increases in those who are pregnant, suffer from bile duct disease, have impaired liver function or have bone disease $[18,36]$. It has been reported that ALP is also related to the nutritional status of the body and has anti-inflammatory effects, which can inhibit the inflammatory response [37]. However, in this study, there were only 5 subjects whose ALB was toward the lower limit of the normal reference range, while only 53 people had ALP toward the upper limit of the normal reference range. In other words, the ALB and ALP levels of $99.49 \%$ of the population in this study were within the normal reference range, so malnutrition, inflammation and immune response do not seem like likely explanations for this association. A lower AAPR may affect the development of NAFLD in unique ways, the underlying mechanism of which is not clear, and further research is needed to explain this hypothesis in the future.

\section{Study strengths and shortcomings}

This study has some unique advantages: (a) This is the first study to explore the association between the AAPR and NAFLD. The findings of this study provide a new idea for the prevention of new-onset NAFLD. (b) This study was a longitudinal cohort design with a large sample size. After strict statistical adjustment and sensitivity analysis, the negative correlation between the AAPR and NAFLD still stably existed, so the conclusion of this study can be considered relatively reliable. (c) The AAPR is the ratio of ALB to ALP, and the measurement of ALB and ALP is very simple and convenient in clinical practice, which is beneficial to the rapid application of the AAPR in clinical practice.

Of course, the shortcomings of this study are also obvious: (a) This study is the first to explore the association between the AAPR and NAFLD, so comparisons with similar studies and two-way verification of related basic research are lacking; therefore, the conclusions of this study should be carefully referred to, and more similar studies are needed to verify it. (b) This study is the second analysis of a previous study [24], and this study population was non-obese; considering that there are great differences between obese and non-obese people, more studies are needed to verify the correlation between the AAPR and NAFLD in obese people [10]. Additionally, although NAFLD-related variables have been widely collected in this study, there are still some variables that cannot be measured or obtained, which may lead to inevitable residual confusion. (c) In this study, the general clinical data and biochemical indicators of the subjects were standard parameters collected during physical examination, and repeated measurements were not carried out at the follow-up visits. Therefore, the impact of dynamic changes in baseline data on NAFLD could not be evaluated in this study. (d) In this study, NAFLD diagnosis was performed by ultrasound only, and no biopsy was conducted. Biopsy is the gold standard method to diagnose NAFLD stage [38]. Ultrasound has low sensitivity for the detection of mild steatosis [39], meaning that the subjects could already have steatosis but be classified as healthy liver. (e) The cohort of this study is made up of Chinese people, so the conclusion is only applicable to the Chinese population, while in other ethnic groups, the conclusion of this study is for reference only.

\section{Conclusions}

In conclusion, this study demonstrated that a low AAPR is an independent predictor of NAFLD in the future. This finding provides new ideas for the prevention of new-onset NAFLD. Additionally, the AAPR is a new, simple, and inexpensive marker with a wide range of clinical application value.

\section{Abbreviations \\ AAPR: Albumin-to-alkaline phosphatase ratio; VIF: Variance inflation factor; LDL-C: Low-density lipoprotein cholesterol; NAFLD: Non-alcoholic fatty liver disease; ALB: Albumin; ALP: Alkaline phosphatase; Cr: Creatinine; BUN: Blood urea nitrogen; GGT: Gamma glutamyl transferase; Cl: Confidence interval; S/ DBP: Systolic and diastolic blood pressures; FPG: Fasting plasma glucose; BMI: Body mass index; AST: Aspartate aminotransferase; TG: Triglyceride; UA: Uric acid; TP: Total Protein; TC: Total cholesterol; DBIL: Direct bilirubin HDL-C: High-density lipoprotein cholesterol; GLB: Globulin; ALT: Alanine aminotransferase; TB: Total bilirubin; HR: Hazard ratio}

\section{Supplementary Information}

The online version contains supplementary material available at https://doi. org/10.1186/s12944-021-01479-9.

Additional file 1: Supplementary Table 1. Association between AAPR and baseline variables. Supplementary Table $\mathbf{2}$. Collinearity diagnostics steps.

\begin{abstract}
Acknowledgements
I would like to thank Dr. Meng Yu for his supervision of the whole research process.
\end{abstract}

Authors' contributions

(i) Concept and design: YZ and GT-S; (ii) Supervision: YZ, CH, MC-Z and GT-S; (iii) Project administration: NP, LZ and MC-Z; (iv) Write and revise manuscripts: All the authors offered help. The authors read and approved the final manuscript.

Funding

No.

Availability of data and materials

The data are available from the 'Dryad' database (www.datadryad.org). 


\section{Declarations}

\section{Ethics approval and consent to participate}

Wenzhou people's Hospital approved the research plan.

\section{Consent for publication}

Not applicable.

\section{Competing interests}

All authors have no competitive interests to disclose.

\section{Author details}

${ }^{1}$ Cardiology Department, Jiangxi Provincial People's Hospital Affiliated to Nanchang University, Nanchang 330006, China. ${ }^{2}$ Gastroenterology Department, Jiangxi Provincial People's Hospital Affiliated to Nanchang University, Nanchang 330006, China. ${ }^{3}$ Pediatrics Department, Lishui People's Hospital, Lishui 323000, China.

Received: 20 March 2021 Accepted: 6 May 2021

Published online: 16 May 2021

\section{References}

1. Manne V, Handa P, Kowdley KV. Pathophysiology of nonalcoholic fatty liver disease/nonalcoholic Steatohepatitis. Clin Liver Dis. 2018;22(1):23-37. https:// doi.org/10.1016/j.cld.2017.08.007.

2. Perumpail BJ, Khan MA, Yoo ER, Cholankeril G, Kim D, Ahmed A. Clinical epidemiology and disease burden of nonalcoholic fatty liver disease. World J Gastroenterol. 2017;23(47):8263-76. https://doi.org/10.3748/wjg.v23.147.8263.

3. Cai J, Zhang XJ, Ji YX, Zhang P, She ZG, Li H. Nonalcoholic fatty liver disease pandemic fuels the upsurge in cardiovascular diseases. Circ Res. 2020;126(5): 679-704. https://doi.org/10.1161/CIRCRESAHA.119.316337.

4. Kim D, Touros A, Kim WR. Nonalcoholic fatty liver disease and metabolic syndrome. Clin Liver Dis. 2018;22(1):133-40. https://doi.org/10.1016/j.cld.201 7.08.010.

5. Marcuccilli M, Chonchol M. NAFLD and chronic kidney disease. Int J Mol Sci. 2016:17(4):562. https://doi.org/10.3390/ijms17040562.

6. Byrne CD, Targher G. NAFLD: a multisystem disease. J Hepatol. 2015;62(1): S47-64. https://doi.org/10.1016/j.jhep.2014.12.012.

7. Armstrong MJ, Adams LA, Canbay A, Syn WK. Extrahepatic complications of nonalcoholic fatty liver disease. Hepatology. 2014;59(3):1174-97. https://doi. org/10.1002/hep.26717.

8. Polyzos SA, Kountouras J, Mantzoros CS. Obesity and nonalcoholic fatty liver disease: from pathophysiology to therapeutics. Metabolism. 2019;92:82-97. https://doi.org/10.1016/.metabol.2018.11.014.

9. Molina-Molina E, Krawczyk M, Stachowska E, Lammert F, Portincasa P. Nonalcoholic fatty liver disease in non-obese individuals: prevalence, pathogenesis and treatment. Clin Res Hepatol Gastroenterol. 2019:43(6): 638-45. https://doi.org/10.1016/j.clinre.2019.04.005.

10. Wang AY, Dhaliwal J, Mouzaki M. Lean non-alcoholic fatty liver disease. Clin Nutr. 2019;38(3):975-81. https://doi.org/10.1016/j.cInu.2018.08.008.

11. Zou Y, Zhong L, Hu C, Sheng G. Association between the alanine aminotransferase/aspartate aminotransferase ratio and new-onset nonalcoholic fatty liver disease in a nonobese Chinese population: a population-based longitudinal study. Lipids Health Dis. 2020;19(1):245. https://doi.org/10.1186/s12944-020-01419-z.

12. Ye Q, Zou B, Yeo YH, Li J, Huang DQ, Wu Y, et al. Global prevalence, incidence, and outcomes of non-obese or lean non-alcoholic fatty liver disease: a systematic review and meta-analysis. Lancet Gastroenterol Hepatol. 2020;5(8):739-52. https://doi.org/10.1016/S2468-1253(20)30077-7.

13. Fan JG, Kim SU, Wong WW. New trends on obesity and NAFLD in Asia. J Hepatol. 2017;67(4):862-73. https://doi.org/10.1016/j.jhep.2017.06.003.

14. Zou Y, Yu M, Sheng G. Association between fasting plasma glucose and nonalcoholic fatty liver disease in a nonobese Chinese population with normal blood lipid levels: a prospective cohort study. Lipids Health Dis. 2020:19(1):145. https://doi.org/10.1186/s12944-020-01326-3.

15. VanWagner LB, Armstrong MJ. Lean NAFLD: a not so benign condition? Hepatol Commun. 2018;2(1):5-8. https://doi.org/10.1002/hep4.1143.

16. Hagström H, Nasr P, Ekstedt M, Hammar U, Stål P, Hultcrantz R, et al. Risk for development of severe liver disease in lean patients with nonalcoholic fatty liver disease: a long-term follow-up study. Hepatol Commun. 2017;2:48-57.
17. Castera L, Friedrich-Rust M, Loomba R. Noninvasive assessment of liver disease in patients with nonalcoholic fatty liver disease. Gastroenterology. 2019;156:1264-1281.e4.

18. Kwo PY, Cohen SM, Lim JK. ACG clinical guideline: evaluation of abnormal liver chemistries. Am J Gastroenterol. 2017;112(1):18-35. https://doi.org/10.1 038/ajg.2016.517.

19. Chan AW, Chan SL, Mo FK, Wong GL, Wong WW, Cheung YS, et al. Albuminto-alkaline phosphatase ratio: a novel prognostic index for hepatocellular carcinoma. Dis Markers. 2015;2015:564057.

20. Chen ZH, Zhang XP, Cai XR, Xie SD, Liu MM, Lin JX, et al. The predictive value of albumin-to-alkaline phosphatase ratio for overall survival of hepatocellular carcinoma patients treated with trans-catheter arterial chemoembolization therapy. J Cancer. 2018;9(19):3467-78. https://doi.org/1 $0.7150 / j c a .26120$.

21. Li H, Li J, Wang J, Liu H, Cai B, Wang G, et al. Assessment of liver function for evaluation of long-term outcomes of intrahepatic Cholangiocarcinoma: a multi-institutional analysis of 620 patients. Front Oncol. 2020;10:525. https://doi.org/10.3389/fonc.2020.00525

22. Baršić N, Lerotić I, Smirčić-Duvnjak L, Tomašić V, Duvnjak M. Overview and developments in noninvasive diagnosis of nonalcoholic fatty liver disease. World J Gastroenterol. 2012;18(30):3945-54. https://doi.org/10.3748/wjg.v18. i30.3945.

23. Sun D-Q, et al. Data from: association of low-density lipoprotein cholesterol within the normal range and NAFLD in the non-obese Chinese population: a cross-sectional and longitudinal study. Dryad, Dataset. 2016. https://doi. org/10.5061/dryad.1n6c4.

24. Sun DQ, Wu SJ, Liu WY, Wang LR, Chen YR, Zhang DC, et al. Association of low-density lipoprotein cholesterol within the normal range and NAFLD in the non-obese Chinese population: a cross-sectional and longitudinal study. BMJ Open. 2016;6(12):e013781. https://doi.org/10.1136/bmjopen-2016-013781.

25. Zeng MD, Fan JG, Lu LG, Li YM, Chen CW, Wang BY, et al. Chinese National Consensus Workshop on nonalcoholic fatty liver disease. Guidelines for the diagnosis and treatment of nonalcoholic fatty liver diseases. J Dig Dis. 2008; 9(2):108-12. https://doi.org/10.1111/j.1751-2980.2008.00331.x.

26. Feng G, Feng L, Zhao Y. Association between ratio of Y-glutamyl transpeptidase to high-density lipoprotein cholesterol and prevalence of nonalcoholic fatty liver disease and metabolic syndrome: a cross-sectional study. Ann Transl Med. 2020;8(10):634. https://doi.org/10.21037/atm-19-4516.

27. Wax Y. Collinearity diagnosis for a relative risk regression analysis: an application to assessment of diet-cancer relationship in epidemiological studies. Stat Med. 1992; 11(10):1273-87. https:/doi.org/10.1002/sim.4780111003.

28. Fitchett EJA, Seale AC, Vergnano S, Sharland M, Heath PT, Saha SK, et al. Strengthening the reporting of observational studies in epidemiology for newborn infection (STROBE-NI): an extension of the STROBE statement for neonatal infection research. Lancet Infect Dis. 2016;16(10):e202-13. https:// doi.org/10.1016/S1473-3099(16)30082-2

29. Tobari M, Hashimoto E, Taniai M, Ikarashi Y, Kodama K, Kogiso T, et al. Characteristics of non-alcoholic steatohepatitis among lean patients in Japan: not uncommon and not always benign. J Gastroenterol Hepatol. 2019;34(8):1404-10. https://doi.org/10.1111/jgh.14585.

30. Gan D, Wang L, Jia M, Ru Y, Ma Y, Zheng W, et al. Low muscle mass and low muscle strength associate with nonalcoholic fatty liver disease. Clin Nutr. 2020;39(4):1124-30. https://doi.org/10.1016/j.cInu.2019.04.023.

31. Xue Z, Yu J, Higashikuchi T, Compher C. Does low body mass index predict mortality in Asian hospitalized patients? JPEN J Parenter Enteral Nutr. 2020; 44(4):722-8. https://doi.org/10.1002/jpen.1708.

32. Flegal KM, Graubard BI, Williamson DF, Gail MH. Excess deaths associated with underweight, overweight, and obesity. JAMA. 2005;293(15):1861-7. https://doi.org/10.1001/jama.293.15.1861.

33. Mendez CM, McClain CJ, Marsano LS. Albumin therapy in clinical practice. Nutr Clin Pract. 2005;20(3):314-20. https://doi.org/10.1177/011542650502 0003314.

34. Garcia-Martinez R, Andreola F, Mehta G, Poulton K, Oria M, Jover M, et al. Immunomodulatory and antioxidant function of albumin stabilises the endothelium and improves survival in a rodent model of chronic liver failure. $J$ Hepatol. 2015;62(4):799-806. https://doi.org/10.1016/j.jhep.2014.10.031.

35. Tanriverdi O. A discussion of serum albumin level in advanced-stage hepatocellular carcinoma: a medical oncologist's perspective. Med Oncol. 2014;31(11):282. https://doi.org/10.1007/s12032-014-0282-3.

36. Al Mamari S, Djordjevic J, Halliday JS, Chapman RW. Improvement of serum alkaline phosphatase to $<1.5$ upper limit of normal predicts better outcome 
and reduced risk of cholangiocarcinoma in primary sclerosing cholangitis. J Hepatol. 2013;58(2):329-34. https://doi.org/10.1016/j.jhep.2012.10.013.

37. Lallès JP. Recent advances in intestinal alkaline phosphatase, inflammation, and nutrition. Nutr Rev. 2019;77(10):710-24. https://doi.org/10.1093/nutrit/ nuz015.

38. Hashimoto E, Taniai M, Tokushige K. Characteristics and diagnosis of NAFL D/NASH. J Gastroenterol Hepatol. 2013;28:64-70. https://doi.org/10.1111/ jgh.12271.

39. Ferraioli G, Soares Monteiro LB. Ultrasound-based techniques for the diagnosis of liver steatosis. World J Gastroenterol. 2019;25(40):6053-62. https://doi.org/10.3748/wjg.v25.140.6053.

\section{Publisher's Note}

Springer Nature remains neutral with regard to jurisdictional claims in published maps and institutional affiliations.

Ready to submit your research? Choose BMC and benefit from:

- fast, convenient online submission

- thorough peer review by experienced researchers in your field

- rapid publication on acceptance

- support for research data, including large and complex data types

- gold Open Access which fosters wider collaboration and increased citations

- maximum visibility for your research: over $100 \mathrm{M}$ website views per year

At $\mathrm{BMC}$, research is always in progress.

Learn more biomedcentral.com/submissions 